\title{
A novel controlled drug-delivery system for growth hormone applied to healing skin wounds in diabetic rats
}

\author{
M. J. GIMENO ${ }^{1}$, F. GARCÍA-ESTEO ${ }^{1}$, N. GARCÍA-HONDUVILLA ${ }^{1}$, \\ J. SAN ROMÁN ${ }^{2}$, J. M. BELLÓN ${ }^{1}$ and J. BUJÁN ${ }^{1, *}$ \\ ${ }^{1}$ Departamento de Ciencias Morfológicas y Cirugía, Facultad de Medicina, Universidad de Alcalá, \\ Ctra N-II, Km 33.600, 28871 Alcalá de Henares, Madrid, Spain \\ ${ }^{2}$ Instituto de Ciencia y Tecnología de Polímeros, CSIC, Madrid, Spain
}

Received 4 March 2002; accepted 2 July 2002

\begin{abstract}
Controlled release systems for drugs, hormones and growth factors can be particularly useful in tissue repair processes. These systems act as a biodegradable support containing the substance to be delivered, allowing their gradual release. In the past years, the local application of growth factors has acquired special relevance as a therapeutic option for use in subjects who show deficient tissue scarring, the hormone dose being the limiting factor for its success. In this study, the in vitro biocompatibility of a copolymer formed by vinylpyrrolidone and 2-hydroxyethyl methacrylate, used as an administration vehicle for $\mathrm{hGH}$, was evaluated. The system was then tested in vivo in terms of its capacity for healing incisional wounds in healthy and diabetic rats. For the in vitro studies, polymer and hormone degradation rates were determined, and polymer biocompatibility was evaluated in fibroblast cultures. In the in vivo experiments, an incision was made in the back of the animals, and polymers discs with/without hGH, were introduced in the aperture. Morphological, immunohistochemical and morphometric evaluations were performed on wound tissue specimens 3-10 days after surgery. In vitro, the polymer was found to be biodegradable and showed no toxic effects on fibroblasts, the hormone being slowly released to the culture medium. In untreated diabetic rats, a delayed skin scarring and cell response were observed, compared to that noted in healthy animals. Skin closure, keratinisation and fibrosis occurred earlier in the presence of the polymer-hGH system. The use of this co-polymer as an administration vehicle for hGH improves the wound scarring process in the pathological setting of diabetes.
\end{abstract}

Key words: Controlled release systems; diabetes; growth hormone; skin; wound healing.

${ }^{*}$ To whom correspondence should be addressed. Phone: (34-91) 885-4540. Fax: (34-91) 885-4885 E-mail: mjulia.bujan@uah.es 


\section{INTRODUCTION}

The administration of growth factors via the systemic route often gives rise to undesirable side-effects [1]. Thus, there is a need for methods that allow the slow, sustained and controlled delivery of different substances, so that these may act on a local scale. It is also necessary to avoid that the substances themselves suffer alteration or inactivation. Thus, controlled release systems need to act as a biodegradable support that can preserve and gradually release the substance to be delivered.

Although wound repair is a complex process involving several cell types [2, 3], the degree and quality of repair can been modulated using different types of growth factors. The efficiency of controlled release systems (collagen sponges, gels, creams, liposomes, different polymers) has been assessed by several research teams [4-7]. However, work in this area requires new contributions aimed at stimulating efficient and rapid repair processes that will re-establish homeostasis in the affected organism as effectively as possible.

In normal conditions, the repair of injured tissue involves an inflammatory process, in which white blood cells [8] act in the first instance, and this is followed by fibroblast proliferation and extracellular matrix remodelling mediated by tissue factors [9] and matrix metalloproteinases (MMPs), respectively. In pathological settings such as diabetes, macrophage infiltration [10] and cell proliferation are delayed [11] along with angiogenesis [12]. Further, collagen deposition is abnormal and there is an early expression of metalloproteinases [13], enzymes which are involved in degrading connective tissue in some pathological conditions.

Several attempts have been made to improve the wound healing process in this type of patient, the topical administration of growth factors (EGF, FGFb, IGF, $\mathrm{TGF} \beta$, PDGF, KGF) being the most common therapeutic choice [14, 15] and combinations of these factors being the most effective [16, 17].

Human growth hormone ( $\mathrm{hGH})$, considered as the anabolic hormone par excellence, is able to provoke scar formation. This has been confirmed both by administering the hormone in the usual manner and in clinical trials. In a situation of deficient scarring, e.g. in diabetic patients [10], administration of hGH to the wound site has been described to improve the regenerative capacity of the skin [18].

Growth hormone has been extensively used in healing skin burns and renal wounds. Studies performed on this hormone have demonstrated a reduced scarring time compared with non-treated subjects $[19,20]$. Low GH levels have been associated with an advanced age [21] and with streptozotocin-induced diabetes [22]. Hence, the beneficial effects of GH have been solely attributed to its exogenous application.

In the present study, we first validated and optimised the use of a co-polymer formed by vinylpyrrolidone and 2-hydroxyethyl methacrylate as an administration vehicle for the controlled release of hGH in vitro, and then went on to explore the in vivo effects of the polymer-hormone system on the skin scarring process in healthy and diabetic rats. 


\section{MATERIALS AND METHODS}

\section{Reagents}

2,2'-Azobisisobutyronitrile (AIBN) was purified by fractional crystallisation from methanol (m.p. 104 ${ }^{\circ}$ C). 2-Hydroxyethyl methacrylate (HEMA) and vinylpyrrolidone (VP) (both from Fluka) were distilled under reduced nitrogen pressure and used without further purification [23]. Ampoules containing 4 I.U. (1.48 mg) of human GH (SaizenR, Serono) and other reagents were used as supplied.

\section{Co-polymer synthesis}

Copolymerisation reactions were performed in a water/ethanol mixture $(1: 1)$ at $50 \pm 0.1^{\circ} \mathrm{C}$. The solutions were oxygen-freed by bubbling nitrogen twice for $30 \mathrm{~min}$ before sealing the system. The concentrations of monomer and initiator (AIBN) used were $10^{-1} \mathrm{M}$ and $1.5 \times 10^{-2} \mathrm{M}$, respectively. The sealed ampoules were immersed in a water bath kept at the polymerisation temperature. After $18-20 \mathrm{~h}$, the contents of the ampoules were poured into a large excess of acetone. The co-polymers were washed with the precipitant mixture and dried under vacuum overnight. Finally the polymers were stirred in water overnight and freeze dried once constant weight had been achieved.

Co-polymer samples were analysed by nuclear magnetic resonance spectroscopy. The average composition of the systems was determined according to a method described elsewhere [24].

\section{Disc preparation}

Discs $300 \mu \mathrm{m}$ thick and $10 \mathrm{~mm}$ in diameter were prepared in a Teflon mould by casting from water/ethanol $(1: 1)$ solutions of the HEMA-VP co-polymer (VPH, $120 \mathrm{mg}$ ). After evaporation and drying at reduced pressure, transparent, clear films were obtained. The discs containing $\mathrm{GH}$ were prepared in a similar way by adding the corresponding amount of hGH (1 I.U.) to the co-polymer solution in the water/ethanol mixture. Under the experimental conditions used, hGH was completely soluble in the system and, thus, a homogeneous distribution of the hormone after evaporation of the solvent may be assumed.

\section{In vitro study}

Polymer degradation. Polymer discs with and without hGH were placed in especially designed chambers and rehydrated at $37^{\circ} \mathrm{C}$ for $15 \mathrm{~min}$ in $2 \mathrm{ml}$ of McCoy medium (Gibco BRL). The polymer fragments were then weighed on a digital precision balance and immersed in $2 \mathrm{ml}$ of $\mathrm{McCoy}$ medium at $37^{\circ} \mathrm{C}$ in a humidified oven in 24-well plates such that the VPH was always in contact with the medium. Weights were determined at 1, 2, 4 and $6 \mathrm{~h}$, and 1, 2, 3, 4, 5 and 6 days to monitor polymer degradation. All the experiments were done in triplicate. 
Growth hormone release. At the follow-up times described above, media were collected and stored at $-80^{\circ} \mathrm{C}$ until the $\mathrm{GH}$ released into the medium was determined. Active hGH was estimated by radioimmunoassay (RIA) according to the method provided in the HGH-CTK Kit (Sorin Biomedica Diagnostics). Briefly, this assay is a non-competitive immunoradiometric procedure based on the use of antibody-coated tubes. These antibodies are two mouse monoclonal antibodies directed against two different epitopes on the hGH molecule. Monoclonal IgG antibody to hGH is fixed on the tube, and labelled monoclonal $\mathrm{IgG}$ antibody to hGH is used as tracer. The assay features a single incubation during which the $\mathrm{hGH}$ contained in samples allows the tracer to bind to the solid phase. After incubation, unbound material is removed by aspiration and washing. The amount of labelled antibody bound to the solid phase is proportional to the amount of hGH present in the sample.

Fibroblast cultures. Small skin biopsies $(n=11)$ were obtained from patients undergoing surgery and transported to the laboratory in minimal essential medium (Gibco BRL) supplemented with antibiotics and antimycotic agents. The skin was cut into small explants under sterile conditions and these were deposited on the surface of $25-\mathrm{cm}^{2}$ culture flasks containing McCoy medium supplemented with 2 mM L-glutamine (Gibco BRL), 10\% foetal bovine serum (Gibco BRL), antibiotics ( $10^{5}$ I.U. penicillin $/ \mathrm{ml}$ and $10^{4} \mu \mathrm{g} / \mathrm{ml}$ streptomycin) (Gibco BRL) and $10 \mathrm{mM}$ Hepes (Gibco BRL) in a humid atmosphere of $5 \% \mathrm{CO}_{2}$ at $37^{\circ} \mathrm{C}$.

Fibroblasts were subcultured to increase the cell population. In the second passage, the fibroblasts were trypsinized and seeded onto 24 -well plates at a density of $5 \times 10^{4}$ cells / well in $2 \mathrm{ml}$ of complete medium and incubated at $37^{\circ} \mathrm{C}$ in a culture oven $\left(5 \% \mathrm{CO}_{2}\right)$ for $24 \mathrm{~h}$. Three study groups were established:

I. Control: fibroblasts incubated in culture medium alone.

II. VPH: fibroblasts incubated in culture medium containing empty polymer discs.

III. $\mathrm{VPH}+\mathrm{GH}$ : fibroblasts incubated in culture medium containing hGH-polymer discs.

The fibroblasts were washed and trypsinized 1, 2, 4 and $6 \mathrm{~h}$, and 1, 2, 3, 4, 5 and 6 days after incubation, when cell counts were performed by the Trypan blue dye exclusion method [25] to establish the number of viable cells. These counts were used to plot a fibroblast growth curve for each study group.

Zymography and Western blotting. To establish the cell response to the hGHpolymer system, we determined the presence of degradative matrix enzymes (MMP-2 and MMP-9). To this end, conditioned media were diluted 1:1 in sample buffer $(0.12$ M Tris-base, pH 6.8 containing 20\% glycerol, $0.04 \%$ bromophenol blue and 6\% SDS). The samples were analysed by a zymographic technique using $10 \%$ SDS-PAGE containing $0.1 \%(\mathrm{w} / \mathrm{v})$ gelatin (Sigma Chemical, Spain) as the substrate. Each lane was loaded with a total protein concentration of $3 \mu \mathrm{g}$ and 
subjected to electrophoresis using a $25 \mathrm{~mA} /$ gel constant current at $4^{\circ} \mathrm{C}$. Gels were washed twice in $50 \mathrm{mM}$ Tris, $\mathrm{pH} 7.4$ containing $2.5 \%$ (v/v) Triton X-100 for $1 \mathrm{~h}$, followed by two 10-min rinses in $50 \mathrm{mM}$ Tris, $\mathrm{pH}$ 7.4. After removal of the SDS, the gels were incubated overnight in $50 \mathrm{mM}$ Tris, $\mathrm{pH} 7.5$ containing $10 \mathrm{mM} \mathrm{CaCl}_{2}, 0.15 \mathrm{M} \mathrm{NaCl}, 0.1 \%$ (v/v) Triton X-100 and $0.02 \%$ sodium azide at $37^{\circ} \mathrm{C}$ under constant gentle shaking. Following incubation, the gels were stained with 0.25\% Coomassie brilliant blue R-250 (Sigma Chemical, Spain) and destained in $7.5 \%$ acetic acid with $20 \%$ methanol. The gelatinase bands appear white on a blue background. The degradative activity of MMP-2 and MMP-9 was semiquantitatively determined by densitometry.

For Western blotting, each culture medium sample was mixed with an equal volume of buffer $(0.12$ M Tris-base, pH 6.8 containing $20 \%$ glycerol, $0.04 \%$ bromophenol blue, $6 \%$ SDS in the absence of 2-mercaptoethanol) and subjected to SDS-PAGE (7-12\% SDS) according to the modified method of Laemmli [26]. After SDS-PAGE, the gels were blotted onto a nitrocellulose membrane (BioRad, Hercules, CA, USA) as described by Towbin and Gordon [27]. Excess protein-binding sites were saturated with Tris-buffered saline $(20 \mathrm{mM}$ Tris-base and $137 \mathrm{mM} \mathrm{NaCl}, \mathrm{pH} 7.6$ ) containing $5 \%$ non-fat dried milk and $0.1 \%$ Tween-20. The blotted membranes were incubated with mouse monoclonal anti-human metalloproteinases (MMP)-2 and -9 (R\&D Systems, UK) (1:1000 dilution in Tris-buffered saline) for $1 \mathrm{~h}$ at room temperature. The immunoreactive protein was developed with peroxidase-conjugated rabbit anti-mouse IgG (Southern Biotechnology Associates, Birmingham, AL, USA; $1: 1000$ dilution in Tris-buffered saline) and subjected to luminescence analysis according to a standard protocol [28].

\section{In vivo study}

Disc implant. 32 male Wistar rats, weighing about $150 \mathrm{~g}$ (6 animals per treatment group and study time), were given two intraperitoneal injections of streptozotocin $(70 \mathrm{mg} / \mathrm{kg})$ in order to provoke diabetes [29]. A further 10 healthy animals were used as controls. Over a period of 30 days, glucose in urine was determined weekly using analytical strips to check that the diabetes had not reverted. An incision, $3 \mathrm{~cm}$ in length, was made in the back of each animal, implanted with the corresponding disc when applicable, and immediately closed with suture thread. The treatment groups set up were: HR group, control, non-treated healthy rats; DR group, control, non-treated diabetic rats; DRP group, polymer-treated diabetic rats; DRPGH group, polymer $+\mathrm{hGH}$-treated diabetic rats. Tissue specimens from the wound were examined at 3, 7 and 10 days post-surgery.

Morphological study. Tissue specimens were obtained by reoperating the animals and included the incision zone along with surrounding tissue. For light microscopy, fragments of skin were fixed by immersion in Bouin solution, embedded in paraffin and cut into $5-\mu \mathrm{m}$ transverse sections using a microtome (Microm, 
Barcelona, Spain). Sections were stained with haematoxylin-eosin and Masson's trichrome stains.

The thickness of the epidermis was estimated by morphometric determinations made by MICRON computerised image analysis of 25 transverse sections of healing and normal skin specimens.

Immunohistochemistry. The anti-MMP-2 monoclonal antibody (The Binding Site, Birmingham, UK) was used in all the experiments and the antigen-antibody reaction followed using the alkaline phosphatase-labelled avidin-biotin technique. The protocol consisted of incubation with the primary antibody diluted in phosphatebuffered saline (PBS) overnight at $4{ }^{\circ} \mathrm{C}$, incubation with IgG-biotin $(1: 400$ in PBS) for $45 \mathrm{~min}$ at room temperature, and labelling with avidin coupled to alkaline phosphatase $(1: 200$ in PBS) for $45 \mathrm{~min}$ at room temperature. The immunogens were developed using the Vector ${ }^{\circledR}$ Red alkaline phosphatase substrate kit (Vector Laboratories, Burlingame, CA, USA). Nuclei were counterstained for 15 min with haematoxylin.

\section{Statistical analysis}

Data from the in vitro experiments were compared using the non-parametric Mann-Whitney $U$-test for independent samples. The level of statistical significance was set at $P<0.05$. Epidermal thickness measurements were compared among groups by one-way analysis of variance and the Student-Newman-Keuls test. All data are expressed as means \pm standard deviation.

\section{RESULTS}

In vitro experiments

Polymer degradation and $h G H$ release. The polymer degradation rate (Table 1) was high during the first $24 \mathrm{~h}$, reaching values of $77 \%$. From this time onwards, the rate of degradation stabilised until day 5 when values of $85 \%$ were recorded. The polymer underwent complete degradation over the subsequent $24 \mathrm{~h}$, leaving only small disassociated deposits that represented $6 \%$ of the polymer.

The pattern of hGH release was concurrent with the degradation of the polymer with which it was associated (Table 1). Thus, during the first $24 \mathrm{~h}$, the release of around $60 \%$ of the total amount of hormone was observed. This release rate decreased during subsequent follow-up times, with rates of $17 \%$ recorded from 24 to $48 \mathrm{~h}$ and of $5 \%$ between 48 and $72 \mathrm{~h}$. This indicates that most of the hormone was gradually released over the first 3 days, representing a cumulative release of around $80 \%$. By day 6 , the cumulative release rate exceeded $99 \%$ and corresponded to the almost complete degradation of the polymer. 


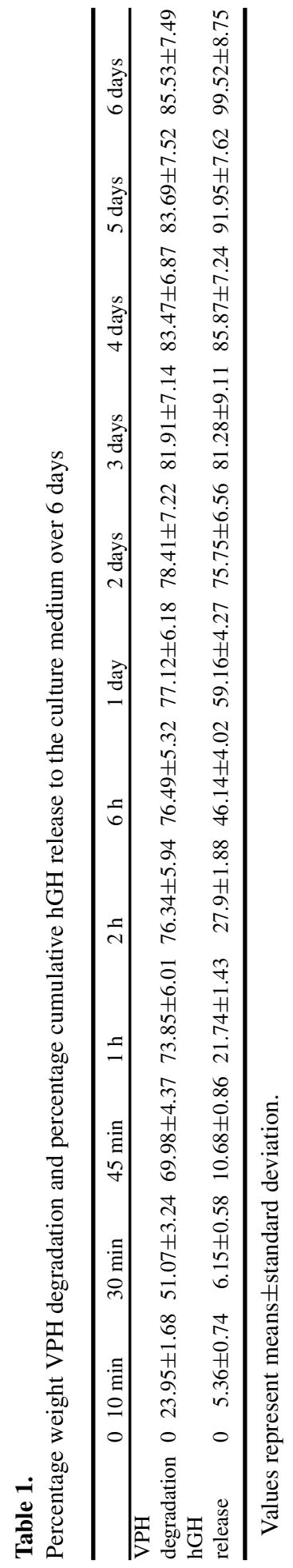




\section{Cell growth}

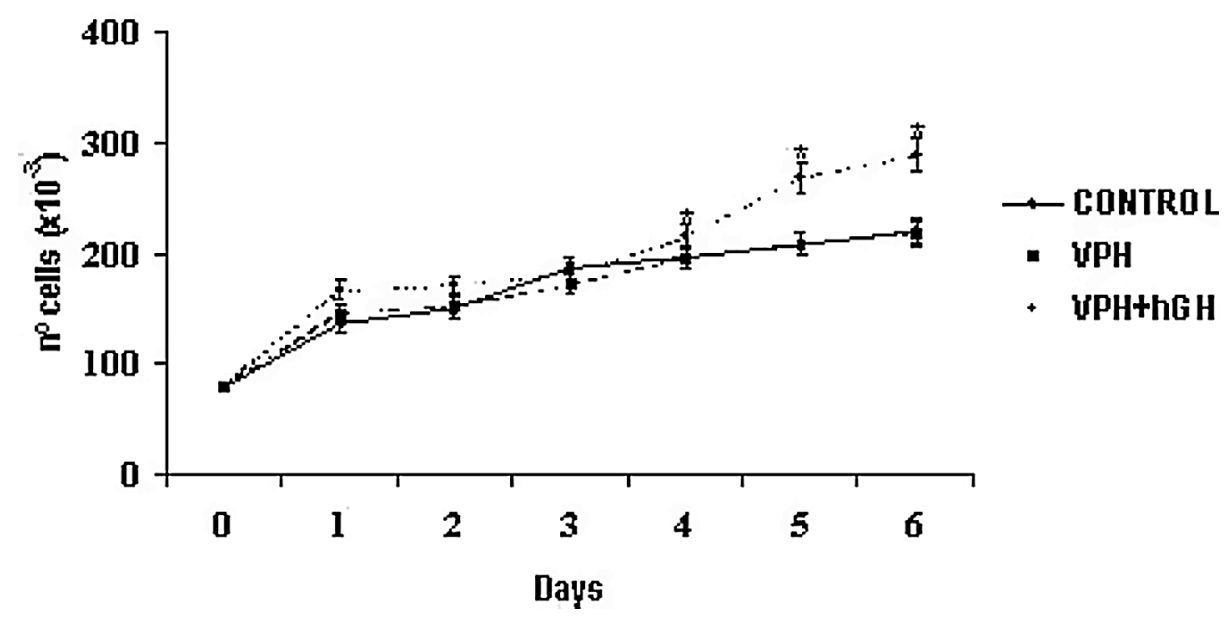

Figure 1. Time-course of fibroblast growth in the presence or absence of VPH + hGH. Results are expressed as mean \pm standard deviation ( $*$ denotes a significant difference, $P<0.05$ ).

Fibroblast growth. These studies demonstrated differences between control and hGH-treated fibroblasts (Fig. 1). During the initial study times, no differences in cell counts were observed among the study groups. However, from the fourth day of culture, control and hGH-treated fibroblasts showed different growth rates and this difference steadily increased until the end of the culture period. In fibroblast cultures incubated with the hGH-loaded polymer, enhanced cell growth was recorded, as compared to the other two groups (control and VPH) from day 4. This difference was maintained until the end of the experiment.

Control and VPH cultures showed a steady increase in fibroblast growth from day 1 to the end of the study. However, fibroblasts treated with hGH-polymer showed enhanced growth from the fourth day onwards.

Zymography and Western blotting. To determine the gelatinolytic activity or the matrix degradative capacity of fibroblasts with or without hGH-polymer (control group), we evaluated the metalloproteinases (MMP-2 and MMP-9) present in conditioned fibroblast culture media.

Zymography indicated the presence of MMP-2 as zymogen, but no MMP-9 degradative response was observed. Bands were quantified by densitometry and no significant differences were observed between groups (Fig. 2).

Immunodetection was aimed at determining MMP-2 and MMP-9 expression. Both MMP-2 and MMP-9 were detected by blotting (Fig. 3). No differences were observed in MMP-2 expression between treated $(\mathrm{GH})$ and non-treated fibroblasts (control). Increased MMP-9 production was observed in both the control and experimental groups as the incubation time increased, but no significant differences between groups were noted on densitometric analysis. 


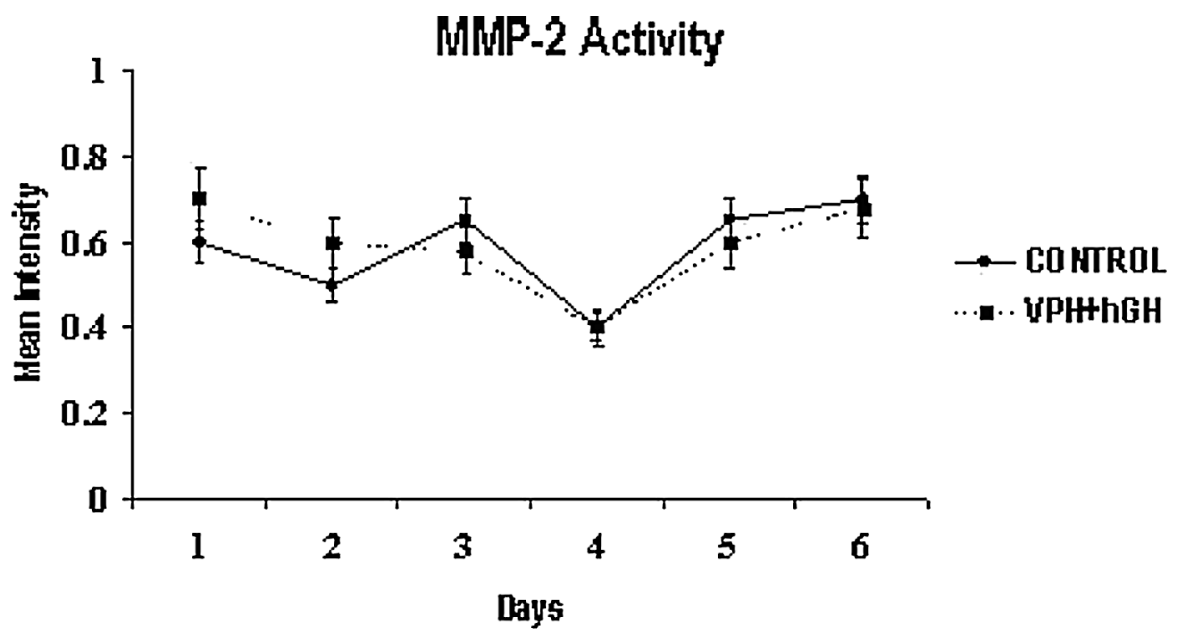

Figure 2. Densitometric analysis of fibroblast gelatinolytic activity. MMP-2 activity is shown as mean intensity rate \pm standard deviation. No significant differences were observed.

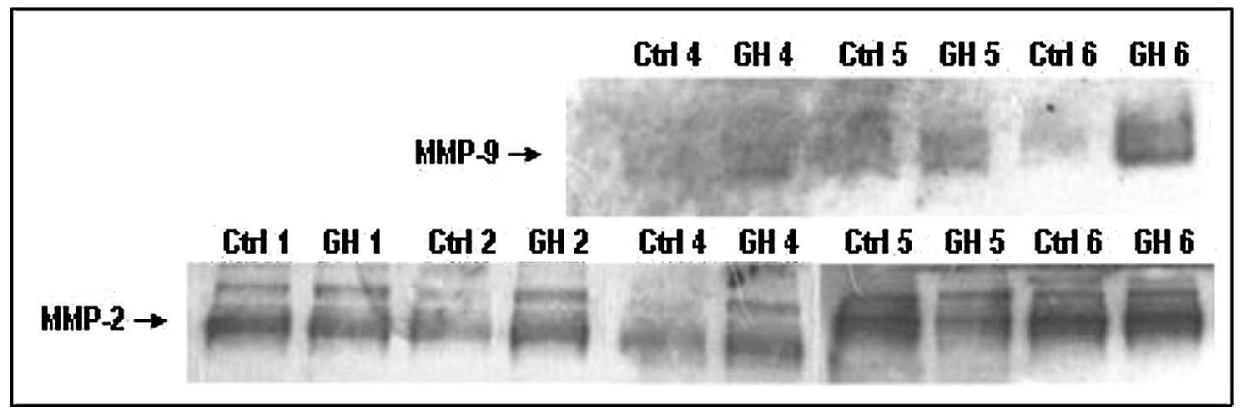

Figure 3. Expression of MMP-2 and MMP-9 in fibroblast cultures grown with (GH) or without (Ctrl) $\mathrm{VPH}+\mathrm{hGH}$ for 6 days. Equal amounts of total protein $(15 \mu \mathrm{g})$ were run on $7 \%$ and $12 \%$ SDS -PAGE gels, respectively.

In vivo experiments

Morphological study. At 3 and 10 days post-surgery, the epidermis and dermis of the wounds created in control, healthy animals (HR) had closed. Normal epidermal thickness had been recovered along the line of incision, values being similar to those for the surrounded tissue. The dermis was composed of dense connective tissue and neovessels penetrated the depths of this layer, approaching the hypodermis and muscle layer.

At 3, 7 and 10 days post-surgery, both the epidermis and dermis of wounds in animals in the DR and DRP groups had not achieved adequate closure (Fig. 4a). Epithelial cells along the edges of the incision had not yet made contact and the wound was plugged by fibrin deposits and cell remains forming a scar. The scarring patterns observed in diabetic animals depended on the treatment group. Improved tissue repair was observed in wounds treated with the hGH-loaded 


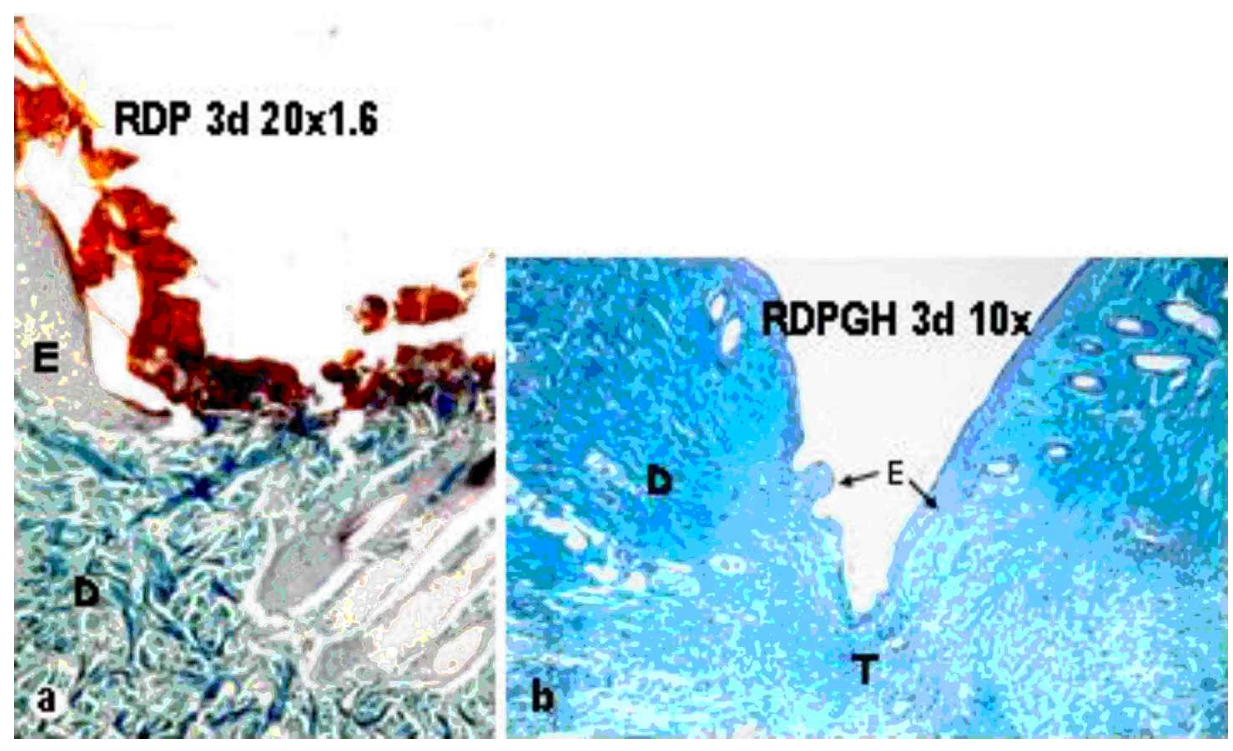

Figure 4. Masson's Trichrome stain. (a) RDP group specimen 3 days after surgery (magnification $320 \times$ ); (b) RDPGH specimen 3 days after surgery (magnification $100 \times$ ). $\mathrm{E}=$ epidermis, $\mathrm{D}=$ dermis, $\mathrm{RT}=$ regenerating tissue. This figure is published in colour on http://www.ingenta.com

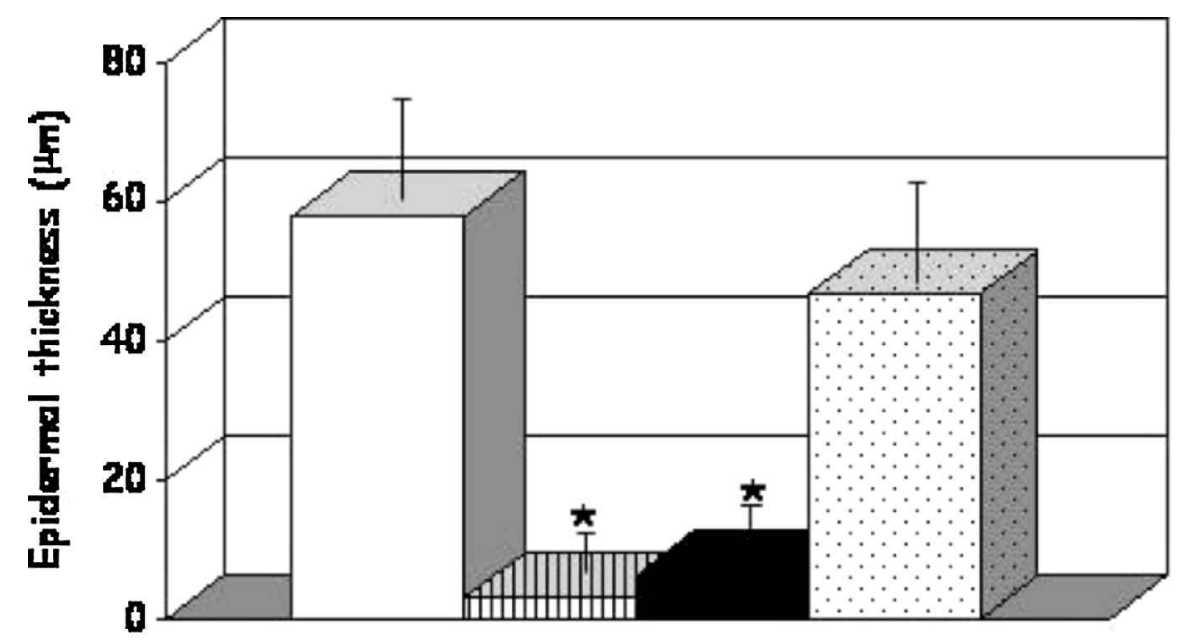

\section{$\square$ NR WIDR $\square$ DPP $\square$ DRPGH}

Figure 5. Epidermal thickness recorded by morphometry. $\left({ }^{*} P<0.01\right.$, Student-Newman-Keuls versus healthy control).

polymer (DRPGH), which showed similar epithelialisation to that observed in wounds in the healthy controls (HR) (Fig. 4b). 
Morphometric analysis of the wounds in healthy and diabetic control animals 7 days after surgery revealed the absence of a neoformed epithelial layer in this last group. At this time of follow-up, hGH treatment of the incisional wounds in diabetic animals improved scar closure over that observed in the DR and DRP groups. The continuous effect of hGH on the wounds induced the formation of a new epithelial layer of values thickness close to those recorded in HR (Fig. 5) at the same study time.

Metalloproteinase expression. Immunohistochemical detection of MMPs in wounds showed a marked increase in MMP-2 expression in the extracellular matrix of the dermis at 3 days (Fig. 6a) post-surgery in DRP with respect to that observed in HR and DRPGH. This immumolabelling decreased with time until reduced to local stains on inflammatory cells close to the polymer remains (Fig. 6b) and within the seroma formed by the biomaterial.

At 3 and 7 days, specimens from HR and DRPGH showed an organised dermis matrix, with a few cells showing positive staining for MMP-2 close to the incision borders and under the epidermal layer.

\section{DISCUSSION}

The idea of using polymeric biomaterials as supports, vehicles or growth control matrices in tissue regeneration processes, has allowed the definition of certain goals that until fairly recently were considered unreachable. An essential requisite for the correct functioning of polymer systems is that there should be adequate synchrony between the processes of reabsorption and regeneration.

In the treatment of skin wounds, it has been established that tissue regeneration is improved when the supply of growth factors is constant [30]. Thus, new methods have been developed for the slow and controlled delivery of different substances so that these may act on a local scale for a prolonged time. These controlled release systems include liposomes used to administer EGF [31], subcutaneously implanted collagen sponges [32] or different polymers delivering a variety of substances [33]. In previous investigations performed in our laboratory, using several vinyl-pyrrolidone polymers comprised of other acrylic monomers, we were able to demonstrate their good dissolution and biocompatibility [34].

In the present study, we used one of these polymer systems, VPH, to act as a support and carrier for agents that stimulate tissue regeneration. Human $\mathrm{GH}$ was tested as one such agent, with the aim of its application in in vivo models. The efficiency of the system was evaluated first in vitro, in terms of its effects on cell growth, and then in vivo, in terms of its effects on scarring in wounds created in the skin of diabetic rats.

In the in vitro experiments performed on fibroblasts, the polymer failed to affect the behaviour of cultures, and fibroblast growth curves showed no significant differences. The pattern of hGH release from the polymer was similar to that 

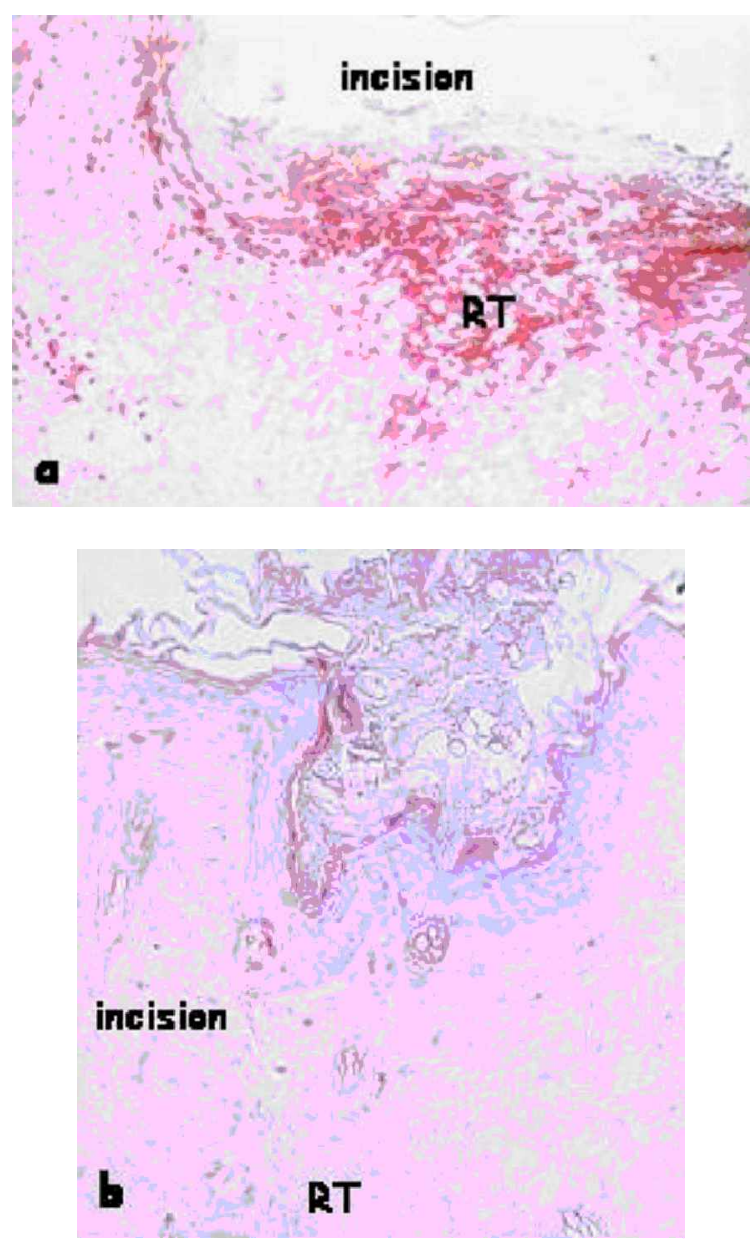

Figure 6. MMP-2 detection by immunohistochemistry. (a) RDP specimen 3 days after surgery. Note the high MMP-2 expression in the area of incision (magnification 200×); (b) RDPGH specimen 3 days after surgery. Scarce MMP-2 expression only can be seen in cells close to line of incision (magnification $200 \times$ ). RT $=$ regenerating tissue. This figure is published in colour on http://www.ingenta.com

described by Downes et al. [35], even considering the different polymers used. In our case, hormone release to the medium showed parallel behaviour to the degradation of the vehicle, as indicated by the polymer degradation curves.

It would appear there is a time period necessary to metabolise the hormone at the cell level, such that its proliferative effects are delayed until 4-5 days of culture. This finding is line with those reported by Nilsson et al. [36] and Stracke et al. [37], who stated the hormone may have a dual effect: a direct action on differentiation and an indirect effect on the production of IGF-1, a potent cell mitogen. Further, it is known that GH modulates the synthesis of cytokines in in vivo repair processes, in which this molecule promotes the appearance of white 
blood cells at the wound site and deposition of the extracellular matrix [38-40]. We found no significant differences among the different study groups in terms of the presence of these metalloproteinases, possibly since in vitro conditions do not always match physiological conditions.

The present findings demonstrate the efficient controlled release of the hormone and the good tolerance of the polymer. No toxicity was shown by the polymer towards the fibroblasts with which it was in contact, and the polymer system was able to slowly release the hormone, preserving its activity and allowing its prolonged effect over several days.

The in vivo studies performed in parallel were designed to confirm our in vitro findings. Skin wounds were created in the loins of healthy and diabetic animals and the behaviour of the wounds was determined in the presence of the polymer and hormone. It was found that the hormone was well-tolerated by the host and that the slow, controlled release of GH achieved improved wound closure in the diabetic animals.

In our study, MMP-2 expression was consistent with the tissue repair process described by Neely et al. [41], in which this MMP plays an active role in the constant remodelling of damaged tissue. In the HR and DRPGH groups, MMP-2 synthesis occurs early on, since at 3 days, the epidermis had completely closed and the dermis was of an organised structure. Conversely, skin wounds corresponding to groups DR and DRP, showed intense expression of this enzyme at this stage in the area of incision and at the level of the matrix and cell.

The presence of polymer in the deep layers of the dermis induced a discrete foreign body reaction around the polymer remains. This reaction was associated with fibrosis that, together with the action of $\mathrm{GH}$, favours the establishment of a newly formed extracellular layer followed by enhanced cell proliferation. Both these factors speed up wound closure and thus reduce complications related to scarring defects in diabetes.

\section{CONCLUSIONS}

The treatment of skin wounds using $\mathrm{GH}$ in a polymer vehicle improved the tissue repair process in diabetic animals. This hormone has been shown to play an important role as a factor for cell survival and proliferation, both in vivo [42] and in vitro [43, 44] and, since it can successfully be incorporated into a polymer substance, it is able to exert its action for several days, improving skin closure.

\section{Acknowledgements}

This work has been supported by grant MAT98-0964-C02-02 from CICYT. 


\section{REFERENCES}

1. H. M. Leibowitz, S. Morello, M. Stern and A. Kupferman, Arch. Ophthalmol. 108, 734 (1990).

2. R. A. Clark, Dermatol. Clin. 11, 647 (1993).

3. A. J. Singer and R. A. Clark, N. Engl. J. Med. 341, 738 (1999).

4. M. C. Berrocal, J. Bujan and A. Aberger, Drug Deliv. 5, 19 (1998).

5. M. S. Agren, Acta Dermatol. Venereol. 78, 119 (1998).

6. F. A. Ismail, J. Napaporn, J. A. Hughes and G. A. Brazeau, Pharm. Dev. Technol. 5, 391 (2000).

7. M. Vlachou, N. Hani, M. Efentakis, P. A. Tarantili and A. G. Andreopoulos, J. Biomater. Appl. 15, 65 (2000).

8. D. E. Boyce, J. Ciampolini, F. Ruge, M. S. C. Murison and K. G. Harding, Br. J. Plast. Surg. 54, $511(2001)$.

9. R. A. Clark, G. A. McCoy, J. M. Folkvord and J. M. McPherson, J. Cell. Physiol. 170, 69 (1997).

10. M. S. Bitar, Horm. Metab. Res. 29, 383 (1997).

11. M. Galeano, V. Torre, B. Deodato, G. M. Campo, M. Colonna, A. Sturiale, F. Squadrito, V. Cavallari, D. Cuccinotta, M. Buemi and D. Altavilla, Surgery 129, 467 (2001).

12. D. Altavilla, A. Saitta, D. Cucinotta, M. Galeano, B. Deodato, M. Colonna, V. Torre, G. Russo, A. Sardella, G. Urna, G. M. Campo, V. Cavallari, G. Squadrito and F. Squadrito, Diabetes 50, 667 (2001).

13. N. Sato, M. Nakamura, T. Chikama and T. Nishida, Jpn. J. Ophthalmol. 43, 343 (1999).

14. G. F. Pierce, T. A. Mustoe, J. Lingelbach, V. R. Masakowski, P. Gramates and T. F. Deuel, Proc. Natl. Acad. Sci. USA 86, 2229 (1989).

15. G. F. Pierce, T. A. Mustoe, J. Lingelbach, V. R. Masakowski, G. L. Griffin, R. M. Senior and T. F. Deuel, J. Cell. Biol. 109, 429 (1989).

16. D. G. Greenhalgh, K. H. Sprugel, M. J. Murray and R. Ross, Am. J. Pathol. 136, 1235 (1990).

17. T. A. Mustoe, G. F. Pierce, C. Morishima and T. F. Deuel, J. Clin. Invest. 87, 694 (1991).

18. K. A. Massey, C. Blakeslee and H. S. Pitkow, J. Am. Podiatr. Med. Ass. 88, 25 (1998).

19. D. N. Herndon, R. E. Barrow, K. R. Kunkel, L. Broemeling and R. L. Rutan, Ann. Surg. 212, 424 (1990).

20. J. P. Barret, P. Dziewulski, M. G. Jeschk, S. E. Wolf and D. N. Herndon, Plast. Reconstr. Surg. 104, 726 (1999).

21. J. W. Finkelstein, H. P. Roffwarg, R. M. Boyar, J. Kream and L. Hellman, J. Clin. Endocrinol. Metab. 35, 665 (1972).

22. J. A. Fagin, C. T. Roberts, D. LeRoith and A. T. Brown, Diabetes 38, 428 (1989).

23. R. J. Fort and T. M. Polyzoidis, Eur. Polym. J. 12, 685 (1976).

24. A. Gallardo, F. Fernández, A. Cifuentes, J. C. Díez-Masa, P. Bermejo, M. Rebuelta, A. LópezBravo and J. San Román, J. Control. Rel. 72, 1 (2001).

25. G. Singh, M. Bohnke, D. von Domarus, J. Draeger, R. L. Lindstrom and D. J. Dougman, Cornea 4, 80 (1985).

26. U. K. Laemmli, Nature 227, 680 (1970).

27. H. Towbin and J. Gordon, J. Immunol. Methods 72, 313 (1984).

28. D. L. Mattson and T. G. Bellehumeur, Anal. Biochem. 240, 306 (1996).

29. T. T. Andreassen and H. Oxlund, Acta Chir. Scand. 153, 405 (1987).

30. S. E. Lynch, R. B. Colvin and H. N. Antoniades, J. Clin. Invest. 84, 640 (1989).

31. G. L. Brown, J. L. Curtsinger, M. White, R. O. Mitchell, J. Pietsch, R. Nordquist, A. von Fraunhofer and G. S. Schultz, Ann. Surg. 208, 788 (1988).

32. F. Berthod, L. Germain, H. Li, W. Xu, O. Damour and F. A. Auger, Matrix Biol. 20, 463 (2001).

33. J. D. Blackman, D. Senseng, L. Quinn and T. Mazzone, Diabetes Care 17, 322 (1994).

34. J. M. Bellon, J. Bujan, L. A. Contreras, A. Carrera-SanMartin and F. Jurado, J. Am. Coll. Surg. 183, 11 (1996).

35. S. Downes, D. J. Wood, A. J. Malcolm and S. Y. Ali, Clin. Orthoped. 252, 294 (1990). 
36. A. Nilsson, J. Isgaard, A. Lindahl, A. Dahlstrom, A. Skottner and O. G. Isaksson, Science 233, 571 (1986).

37. H. Stracke, A. Schultz, D. Moeller, S. Rossol and H. Schatz, Acta Endocrinol. (Copenhagen) 107, 16 (1984)

38. G. Hosgood, Vet. Surg. 22, 490 (1993).

39. D. G. Greenhalgh, J. Trauma 41, 159 (1996).

40. J. Slavin, J. Pathol. 178, 5 (1996).

41. A. N. Neely, C. E. Clendening, J. Gardner, D. G. Greenhalgh and G. D. Warden, Wound Repair Regen 7, 166 (1999).

42. Y. Zaizen, E. G. Ford, H. Shimada, M. Kosi, G. Costin and J. B. Atkinson, Eur. J. Pediatr. Surg. 5, $226(1995)$.

43. M. G. Cascone, B. Sim and S. Downes, Biomaterials 16, 569 (1995).

44. M. Vaalamo, A. L. Kariniemi, S. D. Shapiro and U. Saarialho-Kere, J. Invest. Dermatol. 112, 499 (1999). 
Copyright $\odot 2003$ EBSCO Publishing 